\title{
Impacts of customer incivility and abusive supervision on employee performance: a comparative study of the pre- and post-COVID-19 periods
}

\author{
Yuhyung Shin ${ }^{1} \cdot$ Won-Moo Hur ${ }^{2}$ D Hansol Hwang ${ }^{1}$
}

Received: 26 February 2021 / Accepted: 2 August 2021 / Published online: 6 August 2021

(C) The Author(s), under exclusive licence to Springer-Verlag GmbH Germany, part of Springer Nature 2021

\begin{abstract}
The purpose of our study was to assess the effects of customer incivility and abusive supervision on employee performance during the pre- and post-COVID-19 periods. Our two-wave panel data collected from South Korean frontline service employees revealed that the indirect effect of customer incivility on job performance through emotional exhaustion became more pronounced after the onset of the pandemic. Furthermore, during the pandemic, customer incivility exerted a greater indirect effect on job performance through emotional exhaustion than abusive supervision. These findings offer insights for effectively managing frontline service employees' stress in times of crisis, including pandemics.
\end{abstract}

Keywords COVID-19 $\cdot$ Customer incivility $\cdot$ Abusive supervision $\cdot$ Emotional exhaustion $\cdot$ Job performance

\section{Introduction}

The COVID-19 pandemic has drastically affected society, businesses, and individuals all over the world. While the pandemic has resulted in market shocks and economic downturn (Belso-Martínez et al. 2020), its impact has been most devastating for the service sector (Bajrami et al. 2020; Donthu and Gustafsson 2020; Sönmez et al. 2020). Travel restrictions and social distancing caused by the pandemic have eroded the profitability of airlines, travel agencies, hotels, restaurants, and offline retail stores (Hoang et al. 2021; Wang et al. 2021), which in turn, have induced severe work stress for frontline service employees (FSEs;

Won-Moo Hur

wmhur@inha.ac.kr

$1 \quad$ Hanyang University, Seoul, Korea

2 College of Business Administration, Inha University, 100 Inha-ro, Minchuhol-gu, Incheon 22212, Korea 
Martins et al. 2020). Considering that social capital and network play a pivotal role in assisting employees to cope with COVID-19 (Al-Omoush et al. 2020), it is imperative to explore the social and interpersonal consequences of the pandemic. However, surprisingly few studies have examined the role of interpersonal stressors in FSEs' work attitudes and performance amid COVID-19. Understanding the effect of FSEs' interpersonal stressors in the midst of the pandemic is a crucial research topic because the manner of human interactions has been dramatically changed since the pandemic's onset. New safety rules and devices (e.g., healthcare wearable devices, social distancing screens and dividers, temperature checks, and QR code-enabled contactless check-ins) make it challenging for FSEs to effectively communicate with their customers (Joo and Shin 2020; Lee and Lee 2020), thereby rendering them susceptible to customers' complaints and mistreatment (Voorhees et al. 2020). Therefore, our research aims to assess the effect of interpersonal stressors on FSEs' work attitudes and performance in the COVID19 situation.

Given that FSEs are confronted with interpersonal stress from both inside and outside the organization (Al-Hawari et al. 2020; Arasli et al. 2018; Sliter et al. 2012), examining external and internal sources of interpersonal stress can provide a comprehensive understanding of the roles of different interpersonal stressors during the pandemic. Al-Hawari et al. (2020) found that customer incivility (i.e., discourteous behavior instigated by customers) and abusive supervision (i.e., hostile verbal and nonverbal supervisory behaviors) are the two key interpersonal stressors that FSEs experience at work, which negatively influence their service performance by increasing their emotional exhaustion. Drawing on this finding, we focus on customer incivility and abusive supervision as stressors affecting FSEs' emotional exhaustion and job performance. Emotional exhaustion refers to feeling emotionally exhausted at work (Maslach et al. 1986), whereas job performance is the extent to which employees fulfill the work duties and responsibilities prescribed by their job descriptions (Williams and Anderson 1991).

While recent COVID-19 research has begun to examine the effect of interpersonal stressors (e.g., customer mistreatment) on FSEs' work outcomes in the pandemic context (Ahmed et al. 2021a, b), virtually no research has compared their effect before and after the onset of COVID-19. Comparing the effect of customer incivility and abusive supervision on ESEs' emotional exhaustion and job performance before and during the pandemic is theoretically and practically important. From a theoretical standpoint, investigating whether the deleterious effect of interpersonal stressors is aggravated amid COVID-19 can expand the extant knowledge of workplace interpersonal stressors by proposing the unprecedented pandemic as a boundary condition of such stressors. It also has practical implications for service organizations that strive to manage FSEs' work stressors. If the detrimental effect of customer incivility and abusive supervision turns out to be more severe amid COVID-19, service organizations need to take more proactive actions to prevent or reduce such stressors. Thus, the first objective of our research was to assess whether the negative effects of customer incivility and abusive supervision are aggravated during the pandemic. With this goal in mind, we employed a longitudinal panel design over a 17-month period to compare the relationship between customer 
incivility/abusive supervision-emotional exhaustion-job performance, before and after the onset of COVID-19.

Another gap in prior research is that the relative importance of different interpersonal stressors amid COVID-19 remains unclear. While Al-Harawi et al.'s (2020) findings demonstrated that both customer incivility and abusive supervision negatively affect FSEs' service performance by increasing their emotional exhaustion, their research was conducted in a non-pandemic context, which makes it difficult to assess the differential roles of the two stressors during the pandemic. Thus, the second objective of our research was to determine whether either customer incivility or abusive supervision was more or less detrimental than the other, to FSEs' work attitudes and performance in the midst of the pandemic. By comparing the relative importance of customer incivility and abusive supervision in a pandemic situation, our study provides a nuanced understanding of the role of interpersonal stressors in service contexts, as well as practical implications for effectively managing FSEs' interpersonal stressors.

\section{Theoretical background and hypothesis development}

\subsection{Customer incivility and abusive supervision}

Workplace incivility scholars have called for more research on different interpersonal stressors to delineate their effects on FSEs' work attitudes and performance (Al-Hawari et al. 2020; Cho et al. 2016). Workplace incivility refers to "low intensity deviant behavior with ambiguous intent to harm the target, in violation of workplace norms for mutual respect" (Andersson and Person 1999, p. 457). Incivility differs from other forms of aggressive behaviors - violence, bullying, verbal abuse, or social undermining - in that it represents a milder form of aggressive behavior with less intensity and clarity (Hershcovis and Barling 2010; Kang and Gong 2019; Lim et al. 2008; Welbourne and Sariol 2017). Customer incivility refers to discourteous behavior perpetrated by customers, such as speaking in an uncivil or abusive manner and ignoring the employees' greetings or remarks (Walker et al. 2014).

Abusive supervision, which refers to "the sustained display of hostile verbal and nonverbal behaviors, excluding physical contact" (Tepper 2000, p. 178), is manifested in supervisory behaviors, such as deception, sarcasm, rudeness, and public ridicule (Caesens et al. 2019; Decoster et al. 2014; Tepper 2000). Although it is a high-intensity aggressive behavior, it has an ambiguous intent to harm the target (Glomb 2002; Leblanc and Barling 2005). Thus, customer incivility and abusive supervision have similar characteristics, except for their perpetrators being different, and are deemed as primary interpersonal stressors for FSEs (Avey et al. 2015; Hur et al. 2015). Given that FSEs' interpersonal stress stems from both insiders and outsiders (Al-Hawari et al. 2020), it is reasonable to examine the effects of both customer incivility and abusive supervision on FSEs.

We propose emotional exhaustion as a mediator intervening in the customer incivility-job performance relationship, as well as in the abusive supervision-job performance relationship. This is because emotional exhaustion is the most common 
outcome of workplace mistreatment, including customer incivility and abusive supervision (Al-Hawari et al. 2020; Duffy et al. 2002; Harvey et al. 2007; Sliter et al. 2010). In a similar vein, customer incivility research has identified burnout as a mediator that translates the effect of customer incivility into employee outcomes (Bani-Melhem 2020; Cho et al. 2016; Han et al. 2016). Emotional exhaustion-a key dimension of burnout-refers to the depletion of emotional resources caused by stressors (Demerouti et al. 2003; Maslach and Jackson 1981). Drawing on the aforementioned studies, we propose that customer incivility and abusive supervision negatively affect FSEs' job performance, mainly through emotional exhaustion, and that these relationships get aggravated amid crisis situations, like the COVID-19 pandemic. We present a theoretical background and hypotheses in the subsequent sections.

\subsection{Conservation of Resources (COR) theory}

In line with interpersonal stressor research in pandemic settings (Ahmed et al. 2021a, b), we adopt COR theory (Hobfoll 1989) as a theoretical underpinning for our research model. The underlying assumption of this theory is that people strive to acquire, protect, and preserve their resources. In the COR framework, "resources refer to objects, personal characteristics, conditions, or energies that are valued by the individual, or that serve as a means for attainment of these objects, personal characteristics, conditions, or energies" (Hobfoll 1989, p. 516). According to this framework, interpersonal stressors are the key conditions that drain employees' psychological resources because when they exist in the workplace, they undermine employees' interpersonal relationships (i.e., social resources). As employees expend substantial emotional energies to deal with such stressors, their resources are depleted in the presence of interpersonal stressors. COR theory further postulates a loss spiral of resources in which individuals lacking resources are vulnerable to future resource losses (Hobfoll 1989), which suggests that one stressor makes it difficult for individuals to cope with another. Applying this proposition in the pandemic context, it is reasoned that imminent environmental stressors such as COVID19 causes a resource loss for FSEs and therefore prevent them from coping with interpersonal stressors in the workplace. More detailed explanations for each of our hypotheses are presented in the subsequent sections.

\subsection{Customer incivility, emotional exhaustion, and job performance before and during COVID-19}

Research conducted in non-pandemic situations has denoted a mediating relationship among customer incivility, emotional exhaustion, and job performance (AlHawari et al. 2020; Cho et al. 2016; Han et al. 2016; Kim et al. 2012). In a similar vein, research in pandemic settings has shown that customer mistreatment has a negative relationship with work outcomes (Ahmed et al. 2021a, b). These lines of research use COR theory as a theoretical account for the deleterious effect of customer incivility. More precisely, customer-related interpersonal stressors bring 
about a resource loss for FSEs (Kim et al. 2012), who often engage in emotional labor to display desirable emotions to customers (Ashforth and Humphrey 1993). When interacting with uncivil customers, FSEs need to suppress negative feelings and fake positive emotions toward them (Sliter et al. 2010), which depletes their emotional and psychological resources (Al-Hawari et al. 2020). Thus, after a difficult customer encounter, FSEs become emotionally exhausted and impatient (Cho et al. 2014, 2016). From a COR lens, emotionally exhausted FSEs strive to conserve their depleted resources, thereby, withdrawing from work and not exerting effort in performing their jobs (Al-Hawari et al. 2020).

We predict that the negative indirect effect of customer incivility on job performance through emotional exhaustion will be more pronounced during the COVID-19 pandemic. In the COR framework, environmental circumstances can cause a resource depletion (Hobfoll 1989). We argue that the COVID-19 pandemic is an environmental circumstance that aggravates the resource depletion of customer incivility for the following reasons. First, the economic recession arising from the pandemic has pressurized many organizations to downsize employees or change their work arrangements. As a consequence, many individuals feel anxious about their job security (Filimonau et al. 2020; He et al. 2020; Jung et al. 2021). In addition, telework and social distancing caused by the pandemic render individuals feel lonely and isolated and prevent them from concentrating on their work (Chong et al. 2020). As such, the pandemic has resulted in psychological distress for individuals in diverse occupations. These individuals, when they become customers at the service site, are likely to mistreat FSEs because of their own stress. Second, since the onset of the pandemic, individuals have a greater fear of contracting COVID-19 during employee-customer interactions (Hannerz et al. 2002; Yu et al. 2021). In particular, many customers find hygiene and quarantine policies and use of healthcare applications or devices cumbersome and stressful (Joo and Shin 2020; Lee and Lee 2020; Voorhees et al. 2020), thereby displaying more negative emotions and deviant behaviors toward FSEs. Accordingly, FSEs under the pandemic experience more demands and complaints from customers, which drain their emotional resources to a greater extent than in nonpandemic situations.

Drawing on COR theory, we propose that the COVID-19 pandemic creates a loss spiral, in which the loss of one resource leads to further resource losses (Hobfoll 1989). The pandemic drains customers' psychological resources by rendering them vulnerable to stress resulting from economic recession, job insecurity, and health and safety threats. Because customers are likely to perpetrate more uncivil behaviors toward FSEs during the pandemic, FSEs have more difficulty dealing with such behaviors, which drains their emotional resources. COVID-19 research has reported that FSEs tend to choose a resource-depleting emotion regulation strategy (i.e., emotion suppression) in the pandemic situation (Trougakos et al. 2020). Inhibiting the display of negative feelings toward uncivil customers depletes FSEs' emotional and psychological resources, and therefore, prevents them from effectively coping with customer incivility. Thus, the same level of customer incivility becomes more stressful for FSEs by debilitating their coping capabilities in the pandemic situation. As a consequence, FSEs are likely to exhibit increased emotional exhaustion and 
decreased job performance during the COVID-19 pandemic. This line of reasoning led to the following hypothesis:

H1 The indirect effect of customer incivility experienced by FSEs on job performance through emotional exhaustion is stronger after the onset of COVID-19 than before its onset.

\subsection{Abusive supervision, emotional exhaustion, and job performance before and during COVID-19}

Similar to research on customer incivility, abusive supervision research conducted in non-pandemic settings has demonstrated its negative indirect effect on job performance through emotional exhaustion (Yu et al. 2020), and this relationship can also be explained by COR theory. When FSEs interact with abusive supervisors, they feel that they are deprived of valued resources, such as a high-quality supervisor-subordinate relationship, recognition from the supervisor, increased chances of promotions, etc. (Al-Hawari et al. 2020). Since supervisors are the ones who make important human resource decisions for their subordinates, abusive supervisory behaviors elicit job insecurity perceptions (Park and Ono 2017; Shin and Hur 2020), and feelings of being rejected and worthless among subordinates (Loh et al. 2010; Shin and Hur 2020), which depletes FSEs' emotional resources. Moreover, the unequal supervisor-subordinate relationship dissuades FSEs from displaying negative emotions toward them, which incurs emotional regulation on the part of the employees (Al-Hawari et al. 2020). As a result, FSEs who interact with abusive supervisors feel emotionally exhausted and lack the energy necessary for task accomplishment (Han et al. 2017; Oh and Farh 2017; Pan and Lin 2018; Whitman et al. 2014). This line of reasoning leads to a mediating relationship in which abusive supervision is negatively associated with job performance through emotional exhaustion.

We posit that the proposed mediating relationship is more pronounced in the midst of COVID-19. The COVID-19 pandemic hit the service sector the hardest (Bajrami et al. 2020; Sönmez et al. 2020), posing threats to the job security of service employees and supervisors (e.g., Filimonau et al. 2020; Jung et al. 2021; McKinsey Global Institute 2021). Due to such anxiety and stress triggered by the pandemic, supervisors in the service sector are likely to mistreat their employees, which worsens the resource depletion of abusive supervision in the pandemic context. In this case, FSEs become deficient in the psychological resources that can protect them from interpersonal stressors in the workplace. As proposed by COR theory, the environmental stressor (COVID-19) creates a resource loss for FSEs, which renders them vulnerable to a further resource loss (abusive supervision). In the midst of the COVID-19 pandemic, because FSEs need to expend considerable resources to cope with the pandemic and abusive supervision at the same time, they become emotionally exhausted and feel incompetent and reluctant to devote resources to work. Therefore, we predict that the adverse effect of abusive supervision on job performance through emotional exhaustion will be more severe after FSEs experience the pandemic. Hence, it is hypothesized: 
H2 The indirect effect of abusive supervision experienced by FSEs on job performance through emotional exhaustion is stronger after the onset of COVID-19 than before its onset.

\subsection{Relative effect of customer incivility and abusive supervision during COVID-19}

Although we propose that both customer incivility and abusive supervision negatively affect FSEs' job performance through emotional exhaustion, these two interpersonal stressors are posited to have differential effects on FSEs experiencing the pandemic. Research on workplace incivility suggests that customer incivility exerts a stronger effect on employee outcomes than mistreatment from other sources (AlHawari et al. 2020; Cho et al. 2016; Grandey et al. 2007; LeBlanc and Kelloway 2002). This is attributable to customers' anonymity and customer service norms that inhibit FSEs' retaliation (Diefendorff and Greguras 2006). Unlike interactions with insiders, interactions with customers are often random, anonymous, and do not take place on a regular basis (Cho et al. 2016), which dissuades FSEs from retaliating or venting out their anger on customers. Therefore, customer incivility exhausts FSEs' emotional resources to a greater extent than supervisory mistreatment does (Cho et al. 2016). We claim that such negative effects of customer incivility are reinforced by the COVID-19 pandemic because of increased customer anonymity in such a situation. Since the onset of COVID-19, service organizations require their customers to wear masks and use social distancing screens when interacting with FSEs. This practice makes it difficult for FSEs to identify their customers, which in turn, increases the frequency and intensity of uncivil behavior perpetrated by customers. Furthermore, the new COVID-19 regulations and policies require health and safety actions-temperature checks, QR code-enabled contactless check-ins- to be imposed on customers at the service site, which often reduces the speed of service and provokes more impatient and deviant behaviors, causing stress to FSEs (Voorhees et al. 2020), thereby engendering increased customer complaints (Voorhees et al. 2020). As such, the pandemic creates conditions in which FSEs need to deal with more frequent and intense customer incivility.

We anticipate that customer incivility is more harmful to FSEs than abusive supervision amid COVID-19. This is because FSEs have greater anxieties about infections from customers than from supervisors. Further, since they interact with random and anonymous customers, safety and health anxieties emerging during customer encounters make them more susceptible to resource losses, compared with exposure to abusive supervision. FSEs tend to perceive interactions with uncivil customers to be more stressful than interactions with abusive supervisors during the pandemic, causing customer incivility to be more deleterious than abusive supervision. Moreover, customer encounters involve more emotional labor than interactions with supervisors since FSEs are required to follow emotional display rules during the provision of service (Diefendorff et al. 2006). They become more emotionally exhausted because the COVID-19 pandemic induces them to use resource-depleting emotion regulation strategies (i.e., emotional suppression) in interactions with uncivil customers (Trougakos et al. 2020). 
In addition, given that individuals choose withdrawal behaviors as defensive mechanisms for the pandemic (Trougakos et al. 2020), customer incivility and resulting emotional exhaustion are expected to cause FSEs to withdraw from work. Based on this argumentation, we predict that the negative indirect effect of customer incivility on job performance through emotional exhaustion will be greater than that of abusive supervision in the pandemic context. Therefore, we put forth the following hypothesis:

H3 The indirect effect of customer incivility experienced by FSEs on job performance through emotional exhaustion is stronger than that of abusive supervision after the onset of COVID-19.

\section{Method}

\subsection{Data collection procedure and sample characteristics}

As we targeted FSEs as our sample, we conducted a longitudinal study on South Korean FSEs working in different service organizations (e.g., airlines, hotels, and retail stores) by collecting two-wave longitudinal panel data over a 17-month period, viz., time 1 (T1)=July 2019; time 2 (T2)=December 2020. COVID-19 broke out on January 20, 2020, in South Korea. Since its onset, the South Korean government has issued nationwide social distancing policies.

We contacted South Korean FSEs registered on an online survey platform, and based on the job information that they had submitted to the platform, they were screened and invited to participate in our study through a survey invitation e-mail. Once they agreed to take part, we emailed them an online survey link, along with an informed consent form, which assured voluntary participation as well as the confidentiality and anonymity of the survey responses. A total of 651 FSEs responded to the T1 survey. Seventeen months later, we emailed them a link for the T2 survey. Of the $651 \mathrm{~T} 1$ respondents, 211 completed the T2 survey (retention rate $=32.4 \%$ ). Around $59 \%$ of the respondents were female. Their average age and current job tenure were $35.86(\mathrm{SD}=8.13)$ and 5.29 $(\mathrm{SD}=4.74)$ years, respectively, with diverse education levels, viz., four-year university (47.4\%), two-year vocational college (18.5\%), graduate school $(2.4 \%)$, and high school (31.8\%) (see Table 1).

To test whether there were any systematic differences between the final sample $(N=211)$ and the drop-outs $(N=440)$, we conducted a one-way analysis of variance and found no significant differences between the two groups in terms of both study and control variables, which suggests that non-response did not influence our data (see Table 2). 
Table 1 Demographic characteristics of the participants

\begin{tabular}{llccr}
\hline Variable & Category & $\begin{array}{c}\text { Time1 sample } \\
(N=651)\end{array}$ & $\begin{array}{l}\text { Time2 sample } \\
(N=221)\end{array}$ & $\begin{array}{l}\text { Drop-out sample } \\
(N=440)\end{array}$ \\
\hline Gender & Female & $415(63.7 \%)$ & $124(58.8 \%)$ & $291(66.1 \%)$ \\
& Male & $236(36.3 \%)$ & $87(41.2 \%)$ & $149(33.9 \%)$ \\
Age & 21-29 years & $199(30.6 \%)$ & $52(24.6 \%)$ & $147(33.4 \%)$ \\
& 30-39 years & $246(37.8 \%)$ & $94(44.5 \%)$ & $152(34.5 \%)$ \\
Education & 40-49 years & $149(22.9 \%)$ & $52(24.6 \%)$ & $97(22.0 \%)$ \\
& Ho years and above & $57(8.8 \%)$ & $13(6.2 \%)$ & $44(10.0 \%)$ \\
& Two-year vocational college & $145(22.3 \%)$ & $39(18.5 \%)$ & $106(24.1 \%)$ \\
& Four-year university & $312(47.9 \%)$ & $100(47.4 \%)$ & $212(48.2 \%)$ \\
& Graduate school & $13(2.0 \%)$ & $5(2.4 \%)$ & $8(1.8 \%)$ \\
\multirow{5}{*}{ Job tenure } & Less than 3 year & $291(44.7 \%)$ & $86(40.8 \%)$ & $205(46.6 \%)$ \\
& 3 to less than 5 year & $144(22.1 \%)$ & $42(19.9 \%)$ & $102(23.2 \%)$ \\
& 5 to less than 10 year & $133(20.4 \%)$ & $47(22.3 \%)$ & $86(19.5 \%)$ \\
& Over 20 years & $83(12.7 \%)$ & $36(17.1 \%)$ & $47(10.7 \%)$ \\
\hline
\end{tabular}

Table 2 The results of ANOVA before and after the onset of COVID-19

\begin{tabular}{llll}
\hline Variables & $\begin{array}{l}\text { Mean for final sample } \\
(N=211)\end{array}$ & $\begin{array}{l}\text { Mean for drop-out sample } \\
(N=440)\end{array}$ & $F$ value \\
\hline Positive affectivity & 2.69 & 2.58 & $2.63(\mathrm{p}=$ n.s. $)$ \\
Negative affectivity & 2.97 & 3.12 & $3.84(\mathrm{p}=$ n.s. $)$ \\
Customer incivility & 2.54 & 2.66 & $2.96(\mathrm{p}=$ n.s. $)$ \\
Abusive supervision & 2.59 & 2.67 & $.64(\mathrm{p}=\mathrm{n} . \mathrm{s})$. \\
Emotional exhaustion & 2.23 & 2.20 & $.16(\mathrm{p}=$ n.s. $)$ \\
Job performance & 3.90 & 3.96 & $1.12(\mathrm{p}=$ n.s. $)$ \\
\hline
\end{tabular}

\subsection{Measures}

\subsubsection{Study variables}

We followed Brislin's (1970) back-translated procedure, i.e., measurement items were translated from the original English version into Korean and then back translated into English. Bilingual scholars checked for the equivalence between the original and back-translated versions and corrected minor wording discrepancies (Brislin 1970). Responses to the survey items were made on a five-point Likert-type scale ( $1=$ "strongly disagree," $5=$ "strongly agree"), except for customer incivility, which was assessed with Wilson and Holmvall's (2013) ten-item scale (1 = "never," $5=$ "very often"). Abusive supervision was measured with Mitchell and Ambrose's (2007) five-item scale, which is a shortened version of Tepper's (2000) abusive supervision scale. Time was operationalized as a dummy variable, with $0=$ "before 
the onset of COVID-19," i.e., T1, and 1="after its onset," i.e., T2. Emotional exhaustion was assessed with three items from the Maslach Burnout Inventory (Maslach et al. 1996). Job performance was evaluated with Williams and Anderson's (1991) three-item in-role performance scale.

\subsubsection{Control variables}

Respondents' gender, age, job tenure, positive affectivity, and negative affectivity were controlled in all the analyses because of their potential effects on emotional exhaustion and job performance (Hwang et al. 2020; Shin and Hur 2019). Positive and Negative Affect Schedule Short Forms (Thompson 2007) were used as a measure of positive and negative affectivity. All the measurement items are presented in Table 3.

\section{Results}

Table 2 reports the descriptive statistics, scale reliabilities, and correlations for both the pre- and post-COVID samples. As shown in Table 3, all reliability statistics were greater than 0.70 (Nunnally 1978). We conducted a confirmatory factor analysis and found that the proposed six-factor model (i.e., customer incivility, emotional exhaustion, abusive supervision, job performance, positive affectivity, and negative affectivity) fitted the data well, in an absolute sense at both $\mathrm{T} 1$ and $\mathrm{T} 2\left(\chi_{(335)}^{2}{ }_{T 1 / T 2}=675.05 / 708.30, p<0.05\right.$, comparative fit index $=0.92 / 0.93$, Tucker Lewis index $=0.91 / 0.92$, rootmean-square error of approximation $=0.07 / 0.07$, standardized root-mean-square residual $=0.05 / 0.05)$. In addition, all the study variables displayed a sufficient level of composite reliability, ranging from 0.85 to 0.96 (see Table 4). As reported in Table 4, all the average variance-extracted values were greater than the squared correlation between the focal construct and any of the other constructs (Fornell and Larcker 1981). These findings confirm the reliability and validity of our measurement scales.

Because our data were collected using self-report data, we conducted Harman's one-factor test to check for common method variance (CMV; Podsakoff et al. 2012). Results indicated that one-factor model fitted the data worse than the proposed measurement model at both T1 and T2 $\left(\chi_{(350)}^{2} T 1 / T 2=2531.53 / 3221.48, p<0.05\right.$, $\mathrm{CFI}=0.50 / 0.45, \mathrm{TLI}=0.46 / 0.41, \mathrm{RMSEA}=0.17 / 0.20, \mathrm{SRMR}=0.15 / 0.17$ ). Furthermore, the difference between the two chi-squared values (1856.48/2513.18) was significant $(\mathrm{df}=15, p<0.01)$ at both $\mathrm{T} 1$ and $\mathrm{T} 2$. These findings suggest that it unlikely that CMV affected the study findings.

We tested the proposed mediating effects through path modeling and used the M-plus macro designed by Hayes (2017) and Stride et al. (2015) as an analytic tool. We also ran bootstrapping $(N=5000)$, a statistical resampling method that estimates the standard deviation of a model from a sample using M-plus macro.

Hypothesis 1 proposed that the indirect effect of customer incivility on job performance through emotional exhaustion would be stronger after the onset of COVID-19 than before its onset. Table 5 indicates that the negative indirect effect of 
Table 3 Measurement items

\begin{tabular}{|c|c|}
\hline Construct & Measurement items \\
\hline $\begin{array}{l}\text { Positive } \\
\text { affectivity }^{\mathrm{b}}\end{array}$ & $\begin{array}{l}\text { Determined } \\
\text { Attentive } \\
\text { Inspired }\end{array}$ \\
\hline $\begin{array}{l}\text { Negative } \\
\text { affectivity }^{b}\end{array}$ & $\begin{array}{l}\text { Afraid } \\
\text { Nervous } \\
\text { Ashamed }\end{array}$ \\
\hline Customer incivility $^{\mathrm{a}}$ & $\begin{array}{l}\text { Within the past one month, how often have customers... } \\
\text {...continued to complain despite your efforts to assist them? } \\
\text {...made gestures (e.g., eye rolling, sighing) to express their impatience? } \\
\text {...grumbled to you about slow service during busy times? } \\
\text {...made negative remarks to you about your organization? } \\
\text {...blamed you for a problem that you did not cause? } \\
\text {...used an inappropriate manner of addressing you (e.g., "Hey you")? } \\
\text {...failed to acknowledge your efforts when you have gone out of your way to } \\
\text { help them? } \\
\text {...grumbled to you that there were too few employees working? } \\
\text {...complained to you about the value of goods and services? } \\
\text {... made inappropriate gestures to get your attention (e.g., snapping fingers)? }\end{array}$ \\
\hline Abusive supervision $^{\mathrm{b}}$ & $\begin{array}{l}\text { My supervisor... } \\
\text {...ridicules me } \\
\text {...tells me that my thoughts or feelings are stupid } \\
\text {...puts me down in front of others } \\
\text {...makes negative comments about me to others } \\
\text {...tells me that I am incompetent }\end{array}$ \\
\hline Emotional exhaustion ${ }^{\mathrm{b}}$ & $\begin{array}{l}\text { I feel... } \\
\text {...emotionally drained from my work } \\
\text {...fatigued when I get up in the morning and have to face another day on the job } \\
\text {...working with people all day is really a strain for me } \\
\text {...burned out from my work }\end{array}$ \\
\hline Job performance ${ }^{b}$ & $\begin{array}{l}\text {...perform tasks that are expected of me } \\
\text {...fulfill the responsibilities specified in my job description } \\
\text {...meet the formal performance requirements of my job }\end{array}$ \\
\hline
\end{tabular}

a'Items measured on a scale ranging from 1 "never" to 5 "very often."

bItems measured on a scale ranging from 1 "strongly disagree" to 5 "strongly agree."

customer incivility on job performance through emotional exhaustion was stronger at T2 $(b=-0.162,95 \%$ confidence interval $[\mathrm{CI}][-0.257,-0.090])$ than at $\mathrm{T} 1$ $(b=-0.058,95 \%$ CI $[-0.135,-0.004])$. Furthermore, the indirect effect at T2 was significantly stronger than that at T1 $(b=-0.104,95 \%$ CI $[-0.212,-0.003])$, supporting Hypothesis 1.

Hypothesis 2 predicted that the indirect effect of abusive supervision on job performance through emotional exhaustion would be stronger after the onset 


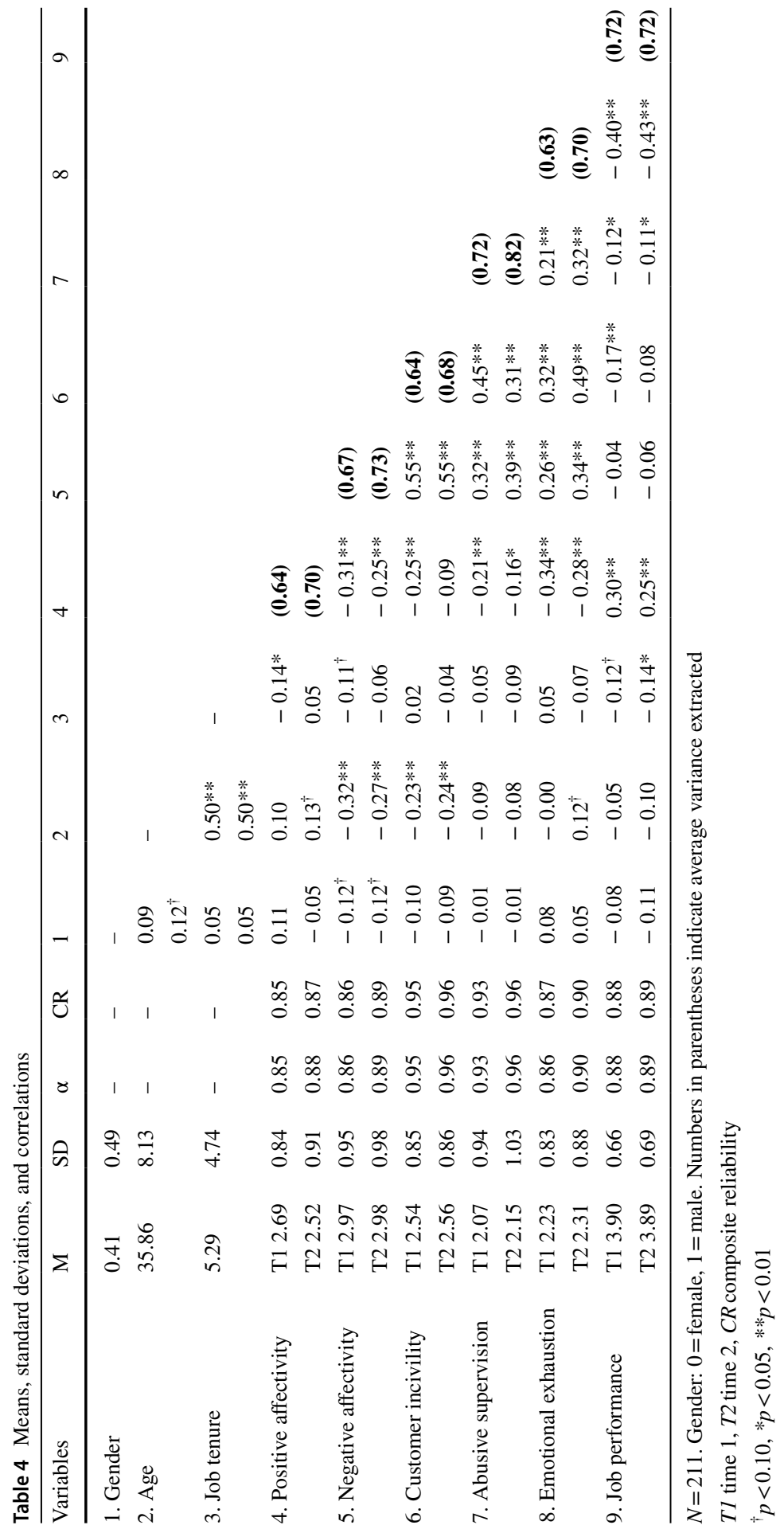


Table 5 The conditional indirect effect of customer incivility and job performance through emotional exhaustion before and after the onset of COVID-19

\begin{tabular}{llll}
\hline Group variable & \multicolumn{2}{l}{$\begin{array}{l}\text { Customer incivility } \rightarrow \text { Emotional exhaus- } \\
\text { tion } \rightarrow \text { Job performance }\end{array}$} \\
\cline { 2 - 4 } Time & $b$ & $\mathrm{Cl}_{95 \% \text { low }}$ & $\mathrm{Cl}_{95 \% \text { high }}$ \\
\hline $\mathrm{T} 2$ & -0.162 & -0.257 & -0.090 \\
$\mathrm{~T} 1$ & -0.058 & -0.135 & -0.004 \\
Difference test & -0.104 & -0.212 & -0.003 \\
\hline
\end{tabular}

T1 time 1, T2 time 2, CI confident interval

of COVID-19 than before its onset. As depicted in Table 6, the negative indirect effect of abusive supervision on job performance through emotional exhaustion was stronger at T2 $(b=-0.047,95 \%$ CI $[-0.101,-0.005])$ than at T1 $(b=-0.006$, 95\% CI $[-0.051,0.041])$. However, since the magnitude of the indirect effects did not significantly differ between T1 and T2 ( $b=-0.041,95 \%$ CI $[-0.110,0.020])$, it failed to support Hypothesis 2.

Hypothesis 3 posited that the indirect effect of customer incivility $(b=-0.162$, $95 \%$ CI $[-0.257,-0.090])$ on job performance would be stronger than the indirect effect of abusive supervision $(b=-0.047,95 \%$ CI $[-0.101,-0.005])$ on job performance after the onset of COVID-19. As shown in Tables 5 and 6, customer incivility and abusive supervision were both negatively associated with job performance through emotional exhaustion, but customer incivility exerted a stronger indirect effect on job performance than abusive supervision $(b=-0.116,95 \% \mathrm{CI}$ $[-0.223,-0.022])$, which supports Hypothesis 3 . The path coefficients for the proposed study (i.e., main effect) model are reported in Fig. 1.

\section{Discussion}

This study's objectives were to assess how the effects of customer incivility and abusive supervision changed before and after the onset of COVID-19 and compare the magnitude of the indirect effects of these two interpersonal stressors in the pandemic context. With these objectives in mind, we conducted a two-wave longitudinal study on 211 FSEs over a 17-month period. The negative indirect effect of customer incivility on job performance through emotional exhaustion appeared to be significantly

Table 6 The conditional indirect effect of abusive supervision and job performance through emotional exhaustion before and after the onset of COVID-19

\begin{tabular}{llcc}
\hline Group variable & \multicolumn{2}{l}{$\begin{array}{l}\text { Abusive supervision } \rightarrow \text { Emotional exhaus- } \\
\text { tion } \rightarrow \text { Job performance }\end{array}$} \\
\cline { 2 - 4 } Time & $b$ & $\mathrm{Cl}_{95 \% \text { low }}$ & $\mathrm{Cl}_{95 \% \text { high }}$ \\
\hline $\mathrm{T} 2$ & -0.047 & -0.101 & -0.005 \\
$\mathrm{~T} 1$ & -0.006 & -0.051 & 0.041 \\
Difference test & -0.041 & -0.110 & 0.020 \\
\hline
\end{tabular}

T1 time 1, T2 time 2, CI confident interval 


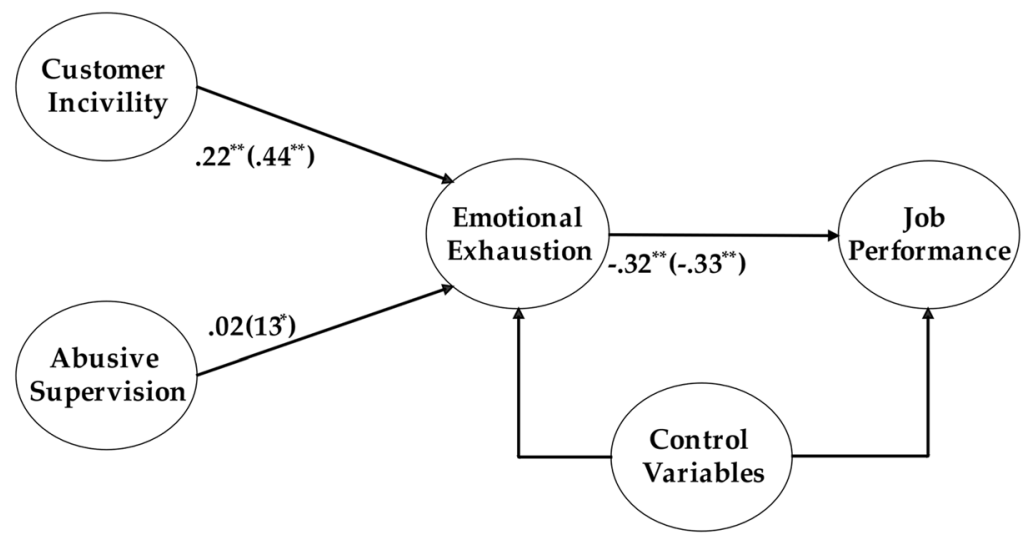

Notes: Unstandardized coefficients for T1 and T2 (in parentheses) variables are reported. For parsimony, the results for the control variables are omitted. ${ }^{*} p<.05,{ }^{* *} p<.01$.

Fig. 1 Path coefficients for the proposed model. Unstandardized coefficients for T1 and T2 (in parentheses) variables are reported. For parsimony, the results for the control variables are omitted. * $p<0.05$, $* * p<0.01$

stronger after the onset of the COVID-19 pandemic than before its onset. However, we found no significant difference in the magnitude of the indirect effect of abusive supervision before and after the onset of the pandemic. As predicted, the indirect effect of customer incivility on job performance through emotional exhaustion was significantly stronger than that of abusive supervision during the pandemic. These findings have implications for theory and practice.

\subsection{Theoretical implications}

Understanding the factors that can undermine FSEs' performance is both theoretically and practically important, considering that their performance is integral to the success of service organizations. In both the non-pandemic (T1) and pandemic (T2) data, customer incivility and abusive supervision decreased FSEs' job performance through emotional exhaustion, which validates prior findings on the relationship between customer incivility, emotional exhaustion, and job performance, as well as the relationship between abusive supervision, emotional exhaustion, and job performance. In response to research, which calls for different interpersonal stressors in the service context (Al-Hawari et al. 2020; Cho et al. 2016), our findings demonstrate that both customer incivility and abusive supervision simultaneously affect FSEs' work attitudes and performance. (Al-Hawari et al. 2020). Our study advances service research by uncovering the roles of different interpersonal stressors in FSEs' work attitudes and performance. 
It also contributes to COR literature by validating COR theory in the pandemic context. Since the majority of COR research has been conducted in non-pandemic settings, it remains unclear whether the COR propositions are applicable to unprecedented pandemics, such as COVID-19. Our findings underscore that the COVID19 pandemic in itself was a severe stressor for FSEs who experienced the pandemic. Even after controlling for FSEs' demographic characteristics and emotion levels, customer incivility exerted a more adverse effect on their emotional exhaustion and job performance after the onset of the pandemic, which suggests that the pandemic was a plausible cause for such a change. According to COR theory, salient and psychologically threatening events lead to a severe loss of resources (Hobfoll 1989). Since the daily media coverage of the COVID-19 pandemic directly affects FSEs, it could be regarded as a salient and psychologically threatening event. Such an event leads to a loss of resources in the COR framework, which accounts for FSEs becoming ill equipped to cope with customer incivility after the onset of the pandemic.

While a growing body of research has examined FSEs' reactions to the COVID19 pandemic, very little research has explored how their stress responses change before and during the pandemic. It is unequivocally true that FSEs suffer from increased stress since the onset of the pandemic. Yet, where their stress comes from and how their stress responses change after being exposed to the pandemic still remain inconclusive. By using two-wave longitudinal data, we were able to compare FSEs' responses to customer incivility and abusive supervision before and during the pandemic. It turned out that the pandemic was more detrimental when FSEs experienced customer incivility than when they experienced abusive supervision. Our findings showed that the deleterious effect of customer incivility was exacerbated after the onset of the COVID-19 pandemic, whereas that of abusive supervision did not change significantly after the pandemic's onset. As such, by revealing how the relationships between customer incivility, emotional exhaustion, and job performance change before and after the pandemic's outbreak, our study contributes to the understanding of interpersonal stressors and FSEs' reactions in the pandemic context.

Of the two interpersonal stressors, customer incivility exerted a greater indirect effect on job performance than did abusive supervision during the pandemic, which is consistent with the finding that indicated a non-significant change in the indirect effect of abusive supervision. An explanation for this finding is that the nature of supervisor-subordinate interaction did not change much since the onset of the pandemic. While virtual work arrangements (e.g., telework and zoom meetings) are prevalent among office workers in the pandemic situation, supervisors in service organizations are required to be present at the service site to monitor their subordinates' performance, which might have caused abusive supervision to have a similar effect on FSEs' emotional exhaustion and job performance before and during the pandemic. However, as mentioned earlier, the manner of customer-employee interaction has changed dramatically since the onset of the COVID-19 pandemic. These changes prevent FSEs from coping with uncivil customers (Voorhees et al. 2020), resulting in increased emotional exhaustion and decreased job performance. Taken together, by unraveling the differential roles of customer incivility and abusive 
supervision in the pandemic context, our study provides the necessary knowledge for helping FSEs cope with interpersonal stressors amid the COVID-19 pandemic.

\subsection{Practical implications}

As the COVID-19 pandemic is an ongoing crisis in many countries, it is vital to understand how different interpersonal stressors affect FSEs' work attitudes and performance in the pandemic context. Based on our findings that customer incivility and abusive supervision exerted a negative indirect effect on job performance through emotional exhaustion during the pandemic, policy makers and practitioners are advised to prevent or reduce these interpersonal stressors in the workplace. They need to pay more attention to customer incivility because this stressor is more harmful to FSEs than abusive supervision in the pandemic situation. Unlike abusive supervision, which can be monitored and corrected by leadership evaluation and training, customer incivility is difficult to eliminate because of customers' anonymity and the unequal power structure between customers and service providers (Sliter et al. 2010). Thus, a more realistic solution to customer incivility would be to enhance FSEs' coping capabilities.

Researchers assert that stress management programs (e.g., relaxation and mindfulness training) can guard FSEs against customer incivility (Frey-Corders et al. 2020; Sliter et al. 2010). Training programs that promote emotion regulation abilities and perspective taking can also help FSEs in understanding the position of customers better and displaying emotions toward them more effectively (Sliter et al. 2010). In particular, given that complicated or unclear guidelines provoke customers' discourteous and deviant behaviors (Voorhees et al. 2020), training programs that educate FSEs on COVID-related rules and safety and health protocols can diminish customer incivility in the pandemic situation. In addition to these training programs, workplace incivility scholars suggest that service organizations should give FSEs a short break after difficult customer encounters (Kim and Qu 2019; Sliter et al. 2010) since it would enable them to recover from stress and recharge their resources. At last, in the light of the findings that social support can alleviate COVID-related stress and anxiety and fortify employees' coping capabilities (Charoensukmongkol and Phungsoonthorn 2020; Hou et al. 2020), service organizations need to provide managerial and peer support for FSEs who are exposed to interpersonal stressors amid the pandemic.

\subsection{Study limitations and directions for future research}

Despite its theoretical and practical implications, our study is subject to several limitations. First, although we argued that the COVID-19 pandemic would deplete FSEs' resources to cope with customer incivility and abusive supervision by evoking concerns for job security as well as anxiety related to health and safety, these mechanisms were neither hypothesized nor tested in our study. Given that recent studies have begun to isolate COVID-19 health anxiety as a mechanism that explains employees' stress during the pandemic (Trougakos et al. 2020), this variable should 
be featured in a research model that aims to precisely capture the changes in employees' reactions to stressors before and after the onset of the pandemic.

Second, our mediation analyses failed to consider any potential moderators that strengthened or weakened the effect of interpersonal stressors in the pandemic context. COVID-19 research has shown that FSEs' emotional intelligence (Frey-Corders et al. 2020) and resilience (Al-Hawari et al. 2020) mitigate the deleterious effect of customer incivility. In addition, social capital and network and collaborative knowledge creation have been found to help organizations and individuals effectively respond to the COVID-19 pandemic (Al-Omoush et al. 2020; Belso-Martínez et al. 2020; López-Cabarcos et al. 2020; Xie et al. 2020). Thus, understanding the role of interpersonal stressors in the pandemic context would be incomplete without taking these moderators into consideration. We recommend that future researchers should examine the moderating effects of emotional intelligence, resilience, and social support in the customer incivility/abusive supervision-emotional exhaustion-job performance relationship.

Third, it should be noted that longitudinal panel designs are vulnerable to the confounding effect of events between the T1 and T2 measurements (Rosnow and Rosenthal 2008). Since there was a 17-month interval between the two measurement points, events other than the pandemic that occurred during this period (e.g., economic recession) might have influenced FSEs' responses at T2. For this reason, we cannot conclude that the changes in FSEs' reactions to interpersonal stressors before and after the onset of the pandemic were solely attributable to the pandemic itself. We encourage future researchers to replicate the current findings by using more control variables (e.g., changes in economic and labor market conditions) in their analyses. Furthermore, because we did not have data for employee-supervisor dyadic tenure, we cannot ascertain that the respondents reported to the same supervisor during the 17-month span. It is possible that due to supervisors' rotation, promotion, or quitting, FSEs might report to different supervisors during the research period, which might have led to non-significant findings for abusive supervision. Given that the duration of employee-supervisor interaction may affect employees' perceptions of abusive supervision, it is necessary to control for the dyadic tenure between the employee and supervisor in future research.

Fourth, although we administered two-wave surveys, we concurrently measured the independent variable, mediator, and dependent variable. Mediating effects can be better estimated in three-wave longitudinal designs. In addition, as we relied on self-reports to measure the study variables, potential CMV might have inflated the relationship between customer incivility/abusive supervision, emotional exhaustion, and job performance. Moreover, self-reported job performance is susceptible to social desirability and evaluation appreciation. To resolve these issues, future research needs to use more objective measures of job performance (e.g., supervisor ratings).

At last, although we drew our sample from diverse service organizations, our sample consisted only of South Korean FSEs. Thus, the cultural characteristics of South Korea might have affected our findings. Due to collectivism (Hofstede 1980), Korean employees have a tendency of avoiding conflict with others and maintaining harmonious relationships, which might have caused interpersonal stressors to have a 
detrimental effect on them. Also, the high power distance found in the Korean culture (Hofstede 1980) might have led supervisors and customers to behave discourteously toward employees. These cultural characteristics might have overestimated the negative effects of customer incivility and abusive supervision in our study. As such, the present findings need to be validated in more diverse cultures.

\section{Conclusion}

Distinct from prior COVID-19 research that examine FSEs' interpersonal stressors during the pandemic, our two-wave longitudinal design over a 17-month period allowed a comparison of the effects of interpersonal stressors before and after the onset of the COVID-19 pandemic. As predicted, the negative effect of customer incivility on FSEs' job performance through was more pronounced after the onset of the pandemic than before its onset. However, there was no significant difference in the magnitude of indirect effect of abusive supervision before and during the pandemic. These findings suggest that customer incivility exerts a stronger negative effect on work outcomes than abusive supervision in the pandemic context. As such, by comparing the relative importance of these interpersonal stressors before and after the onset of the pandemic, our research contributes to a novel and nuanced understanding of the roles of different interpersonal stressors in the pandemic situation.

Funding This work was supported by the research fund of Hanyang University (HY-2021).

\section{Declarations}

Conflict of interest On behalf of all authors, the corresponding author states that there is no conflict of interest.

Ethical approval All procedures performed in studies involving human participants were in accordance with the ethical standards of the institutional and/or national research committee and with the 1964 Helsinki declaration and its later amendments or comparable ethical standards.

Informed consent Informed consent was obtained from all individual participants included in the study.

\section{References}

Ahmed I, Ali M, Usman M, Syed KH, Rashid HA (2021a) Customer mistreatment and insomnia in employees-a study in context of COVID-19. J Behav Sci 31(1):248-271

Ahmed I, Islam T, Ahmad S, Kaleem A (2021b) A COVID-19 contextual study of customers' mistreatment and counterproductive work behavior at coffee cafés. Br Food J. https://doi.org/10.1108/ BFJ-07-2020-0664

Al-Hawari MA, Bani-Melhem S, Quratulain S (2020) Do frontline employees cope effectively with abusive supervision and customer incivility? Testing the effect of employee resilience. J Bus Psychol 35(2):223-240. https://doi.org/10.1007/s10869-019-09621-2 
Al-Omoush KS, Simón-Moya V, Sendra-García J (2020) The impact of social capital and collaborative knowledge creation on e-business proactiveness and organizational agility in responding to the COVID-19 crisis. J Innov Knowl 5(4):279-288. https://doi.org/10.1016/j.jik.2020.10.002

Andersson LM, Pearson CM (1999) Tit for tat? The spiraling effect of incivility in the workplace. Acad Manag Rev 24(3):452-471. https://doi.org/10.5465/amr.1999.2202131

Arasli H, Namin BH, Abubakar AM (2018) Workplace incivility as a moderator of the relationships between polychronicity and job outcomes. Int J Contemp Hosp Manag 30(3):1245-1272. https://doi. org/10.1108/IJCHM-12-2016-0655

Ashforth BE, Humphrey RH (1993) Emotional labor in service roles: the influence of identity. Acad Manag Rev 18(1):88-115. https://doi.org/10.5465/amr.1993.3997508

Avey JB, Wu K, Holley E (2015) The influence of abusive supervision and job embeddedness on citizenship and deviance. J Bus Ethics 129(3):721-731. https://doi.org/10.1007/s10551-014-2192-X

Bajrami DD, Terzić A, Petrović MD, Radovanović M, Tretiakova TN, Hadoud A (2020) Will we have the same employees in hospitality after all? The impact of COVID-19 on employees' work attitudes and turnover intentions. Int J Hosp Manag. https://doi.org/10.1016/j.ijhm.2020.102754

Bani-Melhem S (2020) What mitigate and exacerbate the influences of customer incivility on frontline employee extra-role behaviour? J Hosp Tour Manag 44:38-49. https://doi.org/10.1016/j.jhtm.2020. 05.005

Belso-Martínez JA, Mas-Tur A, Sánchez M, López-Sánchez MJ (2020) The COVID-19 response system and collective social service provision. Strategic network dimensions and proximity considerations. Serv Bus 14(3):387-411. https://doi.org/10.1007/s11628-020-00421-w

Brislin RW (1970) Back-translation for cross-cultural research. J Cross Cult Psychol 1:185-216. https:// doi.org/10.1177/135910457000100301

Caesens G, Nguyen N, Stinglhamber F (2019) Abusive supervision and organizational dehumanization. J Bus Psychol 34(5):709-728. https://doi.org/10.1007/s10869-018-9592-3

Charoensukmongkol P, Phungsoonthorn T (2020) The effectiveness of supervisor support in lessening perceived uncertainties and emotional exhaustion of university employees during the COVID-19 crisis: the constraining role of organizational intransigence. J Gen Psychol. https://doi.org/10.1080/ 00221309.2020 .1795613

Cho CH, Kim TT, Lee G, Lee SK (2014) Testing the stressor-strain-outcome model of customer-related social stressors in predicting emotional exhaustion, customer orientation and service recovery performance. Int J Hosp Manag 36:272-285. https://doi.org/10.1016/j.ijhm.2012.09.009

Cho M, Bonn MA, Han SJ, Lee KH (2016) Workplace incivility and its effect upon restaurant frontline service employee emotions and service performance. Int J Contemp Hosp Manag 28(12):28882912. https://doi.org/10.1108/IJCHM-04-2015-0205

Chong S, Huang Y, Chang C (2020) Supporting interdependent telework employees: a moderated-mediation model liking daily COVID-19 task setbacks to next-day work withdrawal. J Appl Psychol 105(12):1408-1422. https://doi.org/10.1037/ap1000084

Decoster S, Camps J, Stouten J (2014) The mediating role of LMX between abusive supervision and work behaviors: a replication and extension. Am J Bus 29(1):61-75. https://doi.org/10.1108/ AJB-06-2013-0038

Demerouti E, Bakker AB, Vardakou I, Kantas A (2003) The convergent validity of two burnout instruments: a multitrait-multimethod analysis. Eur J Psychol Assess 19(1):12-23. https://doi.org/10. $1027 / / 1015-5759.19 .1 .12$

Diefendorff JM, Greguras GJ (2006) Contextualizing emotional display rules: taking a closer look at targets, discrete emotions and behavioral responses. Singapore Management University Lee Kong Chian School of Business, Singapore

Diefendorff JM, Richard EM, Croyle MH (2006) Are emotional display rules formal job requirements? Examination of employee and supervisor perceptions. J Occup Organ Psychol 79(2):273-298. https://doi.org/10.1348/096317905X68484

Donthu N, Gustafsson A (2020) Effects of COVID-19 on business and research. J Bus Res 117:284-289. https://doi.org/10.1016/j.jbusres.2020.06.008

Duffy MK, Ganster DC, Pagon M (2002) Social undermining in the workplace. Acad Manag J 45(2):331351. https://doi.org/10.5465/3069350

Filimonau V, Derqui B, Matute J (2020) The COVID-19 pandemic and organisational commitment of senior hotel managers. Int J Hosp Manag 91:102659. https://doi.org/10.1016/j.ijhm.2020.102659

Fornell C, Larcker DF (1981) Evaluating structural equation models with unobservable variables and measurement error. J Mark Res 18(1):39-50. https://doi.org/10.1177/002224378101800104 
Frey-Cordes R, Eilert M, Büttgen M (2020) Eye for an eye? Frontline service employee reactions to customer incivility. J Serv Mark 34(7):939-953. https://doi.org/10.1108/JSM-07-2019-0270

Glomb TM (2002) Workplace anger and aggression: informing conceptual models with data from specific encounters. J Occup Health Psychol 7(1):20-36. https://doi.org/10.1037/1076-8998.7.1.20

Grandey AA, Kern JH, Frone MR (2007) Verbal abuse from outsiders versus insiders: comparing frequency, impact on emotional exhaustion, and the role of emotional labor. J Occup Health Psychol 12(1):63-79. https://doi.org/10.1037/1076-8998.12.1.63

Han SJ, Bonn MA, Cho M (2016) The relationship between customer incivility, restaurant frontline service employee burnout and turnover intention. Int J Hosp Manag 52:97-106. https://doi.org/10. 1016/j.ijhm.2015.10.002

Han SJ, Harms PD, Bai Y (2017) Nightmare bosses: the impact of abusive supervision on employees' sleep, emotions, and creativity. J Bus Ethics 145(1):21-31. https://doi.org/10.1007/ s10551-015-2859-y

Hannerz H, Tüchsen F, Kristensen TS (2002) Hospitalisations among employees in the Danish hotel and restaurant industry. Eur J Public Health 12(3):192-197. https://doi.org/10.1093/eurpub/12.3.192

Harvey P, Stoner J, Hochwarter W, Kacmar C (2007) Coping with abusive supervision: the neutralizing effects of ingratiation and positive affect on negative employee outcomes. Leadersh Q 18(3):264280. https://doi.org/10.1016/j.leaqua.2007.03.008

Hayes AF (2017) Introduction to mediation, moderation, and conditional process analysis: a regressionbased approach, 2nd edn. Guilford, New York

He J, Mao Y, Morrison AM, Coca-Stefaniak JA (2020) On being warm and friendly: the effect of socially responsible human resource management on employee fears of the threats of COVID-19. Int J Contemp Hosp Manag 33(1):346-366. https://doi.org/10.1108/IJCHM-04-2020-0300

Hershcovis MS, Barling J (2010) Towards a multi-foci approach to workplace aggression: a meta-analytic review of outcomes from different perpetrators. J Organ Behav 31(1):24-44. https://doi.org/10. 1002/job.621

Hoang TG, Truong NT, Nguyen TM (2021) The survival of hotels during the COVID-19 pandemic: a critical case study in Vietnam. Serv Bus 15(2):209-229. https://doi.org/10.1007/s11628-021-00441-0

Hobfoll SE (1989) Conservation of resources: a new attempt at conceptualizing stress. Am Psychol 44(3):513-524. https://doi.org/10.1037/0003-066X.44.3.513

Hofstede G (1980) Motivation, leadership, and organization: do American theories apply abroad? Organ Dyn 9(1):42-63. https://doi.org/10.1016/0090-2616(80)90013-3

Hou J, Yu Q, Lan X (2020) COVID-19 infection risk and depressive symptoms among young adults during quarantine: the moderating role of grit and social support. Front Psychol. https://doi.org/10. 3389/fpsyg.2020.577942

Hur WM, Moon TW, Han SJ (2015) The effect of customer incivility on service employees' customer orientation through double-mediation of surface acting and emotional exhaustion. J Serv Theory Pract 25(4):394-413. https://doi.org/10.1108/JSTP-02-2014-0034

Hwang H, Hur WM, Shin Y (2020) Emotional exhaustion among the South Korean workforce before and after COVID-19. Psychol Psychother. https://doi.org/10.1111/papt.12309

Joo J, Shin MM (2020) Resolving the tension between full utilization of contact tracing app services and user stress as an effort to control the COVID-19 pandemic. Serv Bus 14(4):461-478. https://doi.org/ 10.1007/s11628-020-00424-7

Jung HS, Jung YS, Yoon HH (2021) COVID-19: the effects of job insecurity on the job engagement and turnover intent of deluxe hotel employees and the moderating role of generational characteristics. Int J Hosp Manag 92:102703. https://doi.org/10.1016/j.ijhm.2020.102703

Kang M, Gong T (2019) Dysfunctional customer behavior: conceptualization and empirical validation. Serv Bus 13(4):625-646. https://doi.org/10.1007/s11628-019-00398-1

Kim H, Qu H (2019) The effects of experienced customer incivility on employees' behavior toward customers and coworkers. J Hosp Tour Res 43(1):58-77. https://doi.org/10.1177/1096348018764583

Kim TT, Paek S, Choi CH, Lee G (2012) Frontline service employees' customer-related social stressors, emotional exhaustion, and service recovery performance: customer orientation as a moderator. Serv Bus 6(4):503-526. https://doi.org/10.1007/s11628-012-0164-8

LeBlanc MM, Barling J (2005) Understanding the many faces of workplace violence. In: Spector PE, Fox S (eds) Counterproductive work behaviour: investigations of actors and targets. American Psychological Association, Washington, pp 41-63. https://doi.org/10.1037/10893-002

LeBlanc MM, Kelloway EK (2002) Predictors and outcomes of workplace violence and aggression. J Appl Psychol 87(3):444-453. https://doi.org/10.1037/0021-9010.87.3.444 
Lee SM, Lee D (2020) Healthcare wearable devices: an analysis of key factors for continuous use intention. Serv Bus 14(4):503-531. https://doi.org/10.1007/s11628-020-00428-3

Lim S, Cortina LM, Magley VJ (2008) Personal and workgroup incivility: impact on work and health outcomes. J Appl Psychol 93(1):95-107. https://doi.org/10.1037/0021-9010.93.1.95

Loh J, Restubog SLD, Zagenczyk TJ (2010) Consequences of workplace bullying on employee identification and satisfaction among Australians and Singaporeans. J Cross Cult Psychol 41(2):236252. https://doi.org/10.1177/0022022109354641

López-Cabarcos MÁ, Ribeiro-Soriano D, Piñeiro-Chousa J (2020) All that glitters is not gold. The rise of gaming in the COVID-19 pandemic. J Innov Knowl 5(4):289-296. https://doi.org/10. 1016/j.jik.2020.10.004

Martins A, Riordan T, Dolnicar S (2020) A post-COVID-19 model of tourism and hospitality workforce resilience. https://doi.org/10.31235/osf.io/4quga

Maslach C, Jackson SE (1981) The measurement of experienced burnout. J Organ Behav 2(2):99-113. https://doi.org/10.1002/job.4030020205

Maslach C, Jackson SE, Leiter MP, Schaufeli WB, Schwab RL (1986) Maslach Burnout Inventory. Consulting Psychologists Press, Palo Alto, pp 3463-3464

Maslach C, Jackson SE, Leiter MP (1996) MBI: Maslach Burnout Inventory. CPP, Sunnyvale

McKinsey Global Institute (2021) The future of work after COVID-19. https://www.mckinsey.com/ featured-insights/future-of-work/the-future-of-work-after-covid-19\#

Mitchell MS, Ambrose ML (2007) Abusive supervision and workplace deviance and the moderating effects of negative reciprocity beliefs. J Appl Psychol 92(4):1159-1168. https://doi.org/10.1037/ 0021-9010.92.4.1159

Nunnally JC (1978) Psychometric theory, 2nd edn. McGraw-Hill, New York

Oh JK, Farh CI (2017) An emotional process theory of how subordinates appraise, experience, and respond to abusive supervision over time. Acad Manag Rev 42(2):207-232. https://doi.org/10. 5465/amr.2014.0347

Pan SY, Lin KJ (2018) Who suffers when supervisors are unhappy? The roles of leader-member exchange and abusive supervision. J Bus Ethics 151(3):799-811. https://doi.org/10.1007/ s10551-016-3247-y

Park JH, Ono M (2017) Effects of workplace bullying on work engagement and health: the mediating role of job insecurity. Int J Hum Resour Manag 28(22):3202-3225. https://doi.org/10.1080/ 09585192.2016.1155164

Podsakoff PM, MacKenzie SB, Podsakoff NP (2012) Sources of method bias in social science research and recommendations on how to control it. Annu Rev Psychol 63:539-569. https://doi.org/10. 1146/annurev-psych-120710-100452

Rosnow RL, Rosenthal R (2008) Assessing the effect size of outcome research. In: Nezu CM, Nezu AM (eds) Evidence-based outcome research: a practical guide to conducting randomized controlled trials for psychosocial interventions. Oxford University Press, Oxford, pp 379-401

Shin Y, Hur WM (2019) When do service employees suffer more from job insecurity? The moderating role of coworker and customer incivility. Int J Environ Res Public Health 16(7):1298. https://doi. org/10.3390/ijerph16071298

Shin Y, Hur WM (2020) Supervisor incivility and employee job performance: the mediating roles of job insecurity and amotivation. J Psychol 154(1):38-59. https://doi.org/10.1080/00223980.2019. 1645634

Sliter M, Jex S, Wolford K, McInnerney J (2010) How rude! Emotional labor as a mediator between customer incivility and employee outcomes. J Occup Health Psychol 15(4):468-481. https://doi. org/10.1037/a0020723

Sliter M, Sliter K, Jex S (2012) The employee as a punching bag: the effect of multiple sources of incivility on employee withdrawal behavior and sales performance. J Organ Behav 33(1):121139. https://doi.org/10.1002/job.767

Sönmez S, Apostolopoulos Y, Lemke MK, Hsieh YCJ (2020) Understanding the effects of COVID-19 on the health and safety of immigrant hospitality workers in the United States. Tour Manag Perspect 35:100717. https://doi.org/10.1016/j.tmp.2020.100717

Stride CB, Gardner S, Catley N, Thomas F (2015) Mplus code for mediation, moderation, and moderated mediation models. http://www.offbeat.group.shef.ac.uk/FIO/mplusmedmod.htm

Tepper BJ (2000) Consequences of abusive supervision. Acad Manag J 43(2):178-190. https://doi. org/10.5465/1556375 
Thompson ER (2007) Development and validation of an internationally reliable short-form of the Positive and Negative Affect Schedule (PANAS). J Cross Cult Psychol 38:227-242. https://doi.org/10. 1177/0022022106297301

Trougakos JP, Chawla N, McCarthy JM (2020) Working in a pandemic: exploring the impact of COVID19 health anxiety on work, family, and health outcomes. J Appl Psychol 105(11):1234-1245. https:// doi.org/10.1037/apl0000739

Voorhees CM, Fombelle PW, Bone SA (2020) Don't forget about the frontline employee during the COVID-19 pandemic: preliminary insights and a research agenda on market shocks. J Serv Res 23(4):363-400. https://doi.org/10.1177/1094670520944606

Walker DD, Van Jaarsveld DD, Skarlicki DP (2014) Exploring the effects of individual customer incivility encounters on employee incivility: the moderating roles of entity (in) civility and negative affectivity. J Appl Psychol 99(1):151-161. https://doi.org/10.1037/a0034350

Wang KY, Ma ML, Yu J (2021) Understanding the perceived satisfaction and revisiting intentions of lodgers in a restricted service scenario: evidence from the hotel industry in quarantine. Serv Bus 15:335-368. https://doi.org/10.1007/s11628-021-00445-w

Welbourne JL, Sariol AM (2017) When does incivility lead to counterproductive work behavior? Roles of job involvement, task interdependence, and gender. J Occup Health Psychol 22(2):194-206. https://doi.org/10.1037/ocp0000029

Whitman MV, Halbesleben JR, Holmes IVO (2014) Abusive supervision and feedback avoidance: the mediating role of emotional exhaustion. J Organ Behav 35(1):38-53. https://doi.org/10.1002/job. 1852

Williams LJ, Anderson SE (1991) Job satisfaction and organizational commitment as predictors of organizational citizenship and in-role behaviors. J Manag 17(3):601-617. https://doi.org/10.1177/01492 0639101700305

Wilson NL, Holmvall CM (2013) The development and validation of the incivility from customers scale. J Occup Health Psychol 18(3):310-326. https://doi.org/10.1037/a0032753

Xie X, Zang Z, Ponzoa JM (2020) The information impact of network media, the psychological reaction to the COVID-19 pandemic, and online knowledge acquisition: evidence from Chinese college students. J Innov Knowl 5(4):297-305. https://doi.org/10.1016/j.jik.2020.10.005

Yu J, Park J, Hyun SS (2021) Impacts of the COVID-19 pandemic on employees' work stress, well-being, mental health, organizational citizenship behavior, and employee-customer identification. J Hosp Mark Manag. https://doi.org/10.1080/19368623.2021.1867283

Yu Y, Xu S, Li G, Kong H (2020) A systematic review of research on abusive supervision in hospitality and tourism. Int J Contemp Hosp Manag 32(7):2473-2496. https://doi.org/10.1108/ IJCHM-12-2019-1004

Publisher's Note Springer Nature remains neutral with regard to jurisdictional claims in published maps and institutional affiliations. 